\title{
Influencias itálicas en los programas decorativos de cubicula y triclinia de época republicana y altoimperial en España. Algunos ejemplos representativos
}

\author{
Carmen Guiral Pelegrin \\ antonio Mostalac Carrillo
}

Las investigaciones llevadas a cabo sobre la pintura romana en España de época republicana y altoimperial han conseguido identificar la presencia de los cuatro estilos y detectar las posibles influencias de origen itálico patentes en los repertorios ornamentales y sistemas compositivos. Estos trabajos han estado encaminados a descubrir la producción de esos talleres, sus áreas de influencia y ámbitos geográficos de actuación ${ }^{1}$.

En la actualidad sabemos con cierta seguridad, que el I y II estilos están bien representados en el cuadrante noreste peninsular ${ }^{2}$, mientras

- Guiral, C. y Mostalac, A, "Avance sobre la difusión de los cuatro estilos pompeyanos en Aragón (España)", Pictores per provincias. (Cahiers d'Archéologie romande 43). Avenches 1987, págs. 233-241; GuIRAL, C. y MostalaC, A., "Las pinturas del Museo Episcopal de Vic (Barcelona)", I. Jornades Internacionals d'Arqueologia romana. Granollers 1987, págs. 379-386; Guiral, C. y MostalaC, A., "Pintura romana en Aragón», GEA, Apéndice II. Zaragoza 1987, págs. 270-274; Mostalac, A. y GuIRAL, C., "Preliminares sobre el repertorio ornamental del III y IV estilos pompeyanos en la pintura romana en España", Italica. Cuadernos de Trabajos de la Escuela Española de Historia y Arqueologia en Roma 18 (1991), págs. 155-173; MostALAC, A. y Guiral, C., "Decoraciones pictóricas y cornisas en estuco del Cabezo de Alcalá de Azaila (Teruel)", Revista d'arqueologia de Ponent (1992), págs. 123-150; GuIRAL, C. y MostaLAC, A., "La pintura mural romana de Arcobriga (Monreal de Ariza, Zaragoza)", I Coloquio de Pintura mural romana en España. Valencia 1992, págs. 99-105; MOSTALAC, A., "La pintura romana en España. Estado de la cuestión", Anuario del Departamento de Historia y Teoría del Arte IV (1992), págs. 9-92.

2 Mostalac, A., Catálogo de la pintura romana y cornisas en estuco del Museo de Zaragoza. La Colonia Victrix lulia Lepida Celsa. Zaragoza 1990. GuIRAL, C., Bilbilis. Decoración pictórica y estucos ornamentales. Zaragoza 1990. GuIRAL, C.; MostalAC, A., "Pictores y albarii en el mundo romano", Artistas y artesanos en la España romana. Mérida 1991 (en prensa). 
que el III y el IV se extienden por toda la Península de forma más homogénea ${ }^{3}$. Esta desigualdad se debe, sin duda, a la existencia de yacimientos que han aportado mayor información permitiendo formular conclusiones más sólidas, debido a una investigación extensiva y sistemáti$\mathrm{ca}^{4}$. Pero son todavía escasos, por el momento, los yacimientos que permiten establecer la evolución estilística de la pintura de esta época en España y debemos contentarnos con descubrir o entresacar aspectos particulares que demuestran la presencia de talleres foráneos o cartones importados.

El trabajo que presentamos está encaminado a demostrar, a través de una serie de ejemplos significativos, la presencia en nuestro país de pintores y talleres de origen itálico, en muchas ocasiones con cierta influencia campana. Sin embargo, estas deducciones que provenian únicamente del terreno pictórico, derivan en esta ocasión del estudio conjunto de arquitectura, pavimentos, pinturas y estucos. Es verdad, que hasta el momento, dentro de los programas decorativos de las estructuras domésticas de época republicana, eran los pavimentos de opus signinum los que a través de su composición y repertorios permitian establecer estrechas relaciones con los procedentes del suelo itálico, de tal suerte, que la cronología de los segundos se aplicaba sin reservas a los hallados en suelo hispano. De esta forma el influjo romanizador precoz, deducido de la presencia de este tipo de pavimentos, quedaba explicado en aquellas casas de cronología antigua aunque no poseyeran otros elementos decorativos, ni se pudiera demostrar el origen de sus propietarios, hecho que en principio explicaría el porqué de la presencia de este tipo de suelos, de moda en el período cronológico elegido en este trabajo. De todas formas no deja de ser sorprendente que la mayoría de los pavimentos de opus signinum hallados en España, casi nunca hayan aparecido asociados a pinturas relacionables con los estilos pompeyanos, salvo honrosas excepciones, o a otros detalles de tipo arquitectónico decorativo que hubieran ayudado a matizar este tipo de influencias.

Para ello, hemos seleccionado de la vivienda doméstica de época republicana y altoimperial dos tipos de habitaciones diferentes, cubicula y triclinia, que debido, por una parte, a sus funciones y representatividad dentro del esquema orgánico de la casa y, por otra, a sus peculiaridades intrínsecas, permiten establecer por comparación cómo la influencia de la casa itálica alcanza con cierta precocidad nuestro territorio, quedando patente en una serie de rasgos, tales como:

\footnotetext{
Mostalac, A. y Guirac, C., op. cit. (1991).

Ver nota 2
} 
- La adecuación de la decoración a la arquitectura.

- La funcionalidad de ciertas habitaciones que viene marcada no sólo por el diseño arquitectónico y la posición que ocupa en la planta, sino también por los programas decorativos.

- La existencia de un programa unitario, elaborado conjuntamente por arquitectos, pintores, musivarios y estucadores con el fin de satisfacer el encargo del cliente o manifestar el progresismo impuesto por la moda del momento.

Sin duda es Pompeya la ciudad que, debido a sus vicisitudes históricas, influencias culturales y estado de conservación, aporta mayor información sobre el tipo de estancias objeto de este estudio, cuyas principales características pasamos a analizar.

\section{CUBICULA}

\subsection{Estilo. (Caracteristicas generales)}

Los cubicula o dormitorios relacionados con pinturas del I estilo, se caracterizan por presentar una doble estructura arquitectónica definida por una alcoba y una antecámara. La primera aparece elevada ligeramente respecto de la segunda, lo suficiente para distinguirla con claridad. Este aspecto se realza mediante dos pilastras sobresalientes en la división de la alcoba y la antecámara. La disposición, así como la decoración de sus paredes, denotan un gusto inicial típicamente helenístico ${ }^{5}$, que sorprende con la pavimentación, más sobria de los opera signina. Esta moda en Pompeya no es anterior a finales del siglo 111 o comienzos del 11 a.C. Sin embargo, todavía existen rasgos más particulares fundamentalmente en la decoración de las paredes y de los techos. En la alcoba, la decoración es de menor escala que en la antecámara y también es diferente la forma de los techos que en una suele ser plano y en la otra abovedado. Esta división queda perfectamente delimitada, como ya hemos indicado, por pilastras de estuco que ayudan a separar nítidamente los espacios y las funciones de cada uno ${ }^{6}$.

5 Adriani, A., Repertorio d'Arte dell'Egitto Greco-romano, Serie C, V. 1-2. Palermo 1963, pág. 139, fig., Q n. ${ }^{\circ}$ 188. Rouveret, A., Histoire et imaginaire de la peinture anciénne, Ecole Française de Rome. Rome 1989, págs. 179 ss.

6 ElIA, O., "l cubiculi nelle case di Pompei». Historia 6 (1932) págs. 394-409. BARBET, A., La peinture murale romaine. Les styles décoratifs. Paris 1985, págs. 31-32. LAIDLAW, A., The First Style in Pompei: Painting and Architecture. Roma 1985, págs. 31-32. CLARKE, J.R., "The nonalignement of functional dividers in mosaici and wall painting at Pompeil', Bulletin de I'AIEMA, 
En España, los dos únicos casos conocidos hasta el momento relacionados con pinturas del I estilo, proceden de Contrebia Belaisca (Botorrita, Zaragoza) y de Caminreal (Teruel).

\subsubsection{Contrebia Belaisca}

La ciudad de Contrebia Belaisca se encuentra situada en las proximidades de la actual Botorrita, sobre el río Huerva. Sus restos arqueológicos se fechan desde el siglo III a.C. hasta época imperial romana ${ }^{7}$. En la zona baja del yacimiento destaca por su importancia una domus de época republicana con un marcado influjo helenístico, tanto en su planta como en sus pinturas, de la cual nos interesa destacar el cubículo (4) ${ }^{8}$ (fig. 1). Éste, situado en el flanco derecho del ingreso a la casa, presenta forma irregular y comparte la zona de ingreso con la denominada estancia (5), definida como triclinio. Sus dimensiones máximas son $3 \mathrm{~m}$ de longitud por $2 / 2,70 \mathrm{~m}$ de anchura, debido a su irregularidad y al entrante que presenta en su planta. Estuvo pavimentado con opus signinum destacando las esvásticas y temas estrellados en su composición ${ }^{9}$. La decoración pictórica fue muy simple: el zócalo pintado de negro y la zona media roja, resaltando en el último tercio de la habitación una pilastra estucada de color blanco. Ignoramos si en la zona media hubo despiece de sillares ${ }^{10}$, incisiones, como en el corredor junto al ala (9) ${ }^{11}$, $u$ otro tipo de elementos en relieve ${ }^{12}$. Ciertamente los restos pictóricos dados a conocer recientemente, como los que publicamos en 1987 procedentes de esta misma casa, pertenecen al I estilo pompeyano con un marcado influjo helenístico ${ }^{13}$, al igual que los provenientes de Belmonte de Calatayud ${ }^{14}$.

fasc 12, (1988-1989), págs. 313-321. CLARKE, J.R. «Relationships between floor, wall, and ceiling decoration at Rome and Ostia Antica", Bulletin de l'AlEMA, fasc. 10 (1985), págs. 93-103. CLARKE, J.R., The houses of Roman Italy 100 B.C.-A.D. 250 ritual, space and decoration. University of California 1991. También es interesante la obra, GAZDA, E.K., Roman arte in the private sphere: new perspectives on the architecture and decor of the domus, villa, and insula. University of Michigan 1991.

7 Beltrán, A., "Las casas del poblado de Contrebia Belaisca. Planteamiento de problemas y estado de la cuestión". La casa urbana hispanorromana. Zaragoza 1991, pág. 184. Idem, "Contrebia Belaisca, Botorrita", Arqueología 92. Zaragoza 1992, págs. 239-242.

\& Beltrán, A., op. cit., (1992), fig. 214.

9 BeltaÁn, A., op. cit., (1991), págs. 186-187.

10 Según M. Beltrán hubo pinturas del l estilo en las estancias 3-6 y 9-14. Cfr. BELTRÁN. M. "Roma: República y Alto Imperio» en Estado actual de la Arqueología en Aragón. T.I, Ponencias. Zaragoza 1990, pág. 219, nota 13.

11 Beltrán, A., op. cit., (1991), pág. 200, fig. 27.

12 Guiral, C. y Mostalac, A., op. cit., (1987), pág. 235.

13 Los ejemplos que más se aproximan a nuestro caso provienen de Delos. Cf. BuLARD, M., Peintures et mosaïques de Dèlos (Monuments et Memoires. Fondation E. Piot. XIV). Paris 1908, 


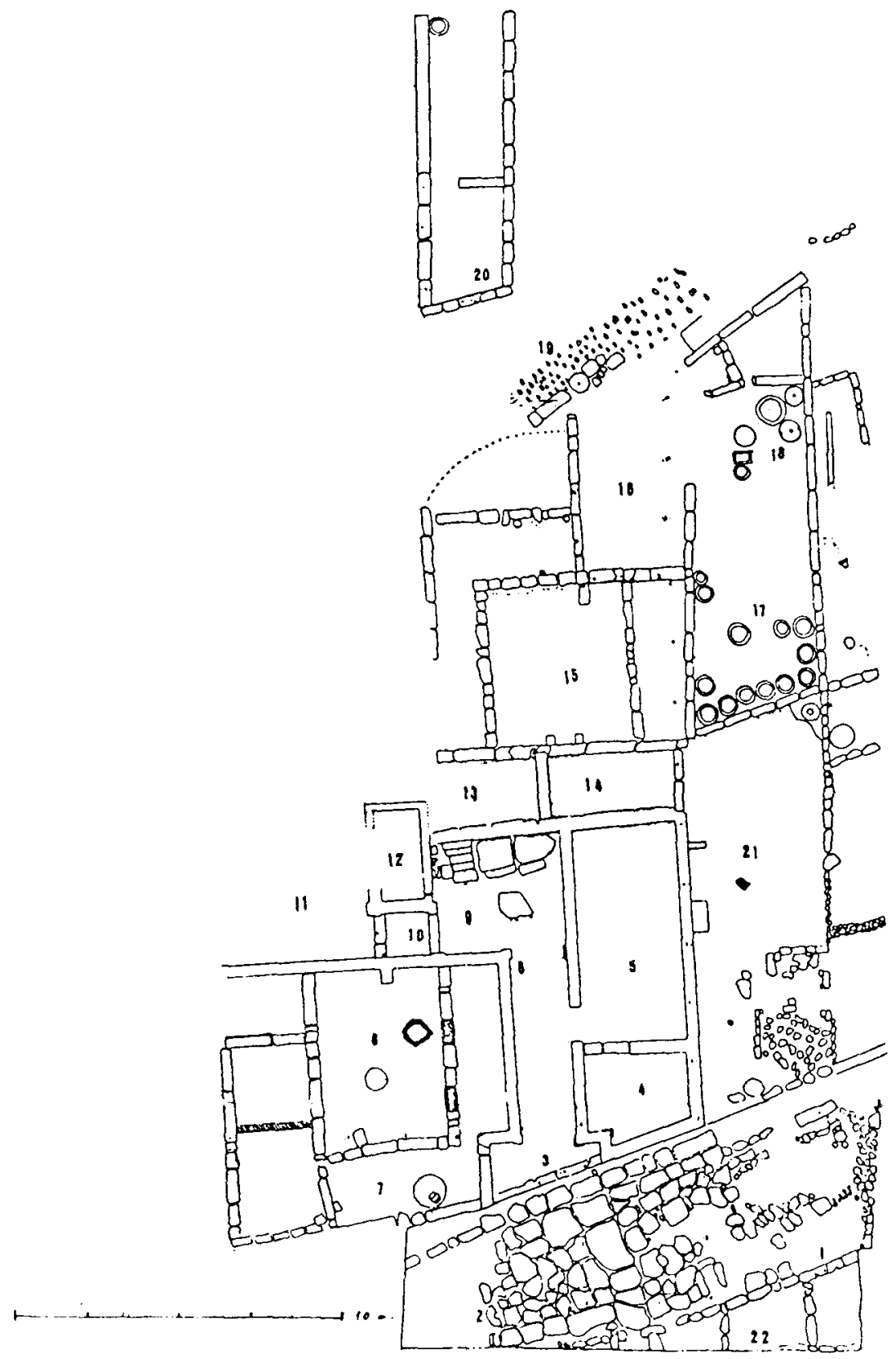

Fig. 1 Contrebia Belaisca (Botorrita, Zaragoza). Casa Agrícola, (sg. A. Beltrán Martmez). 
Sin embargo, además de los ragos pictóricos que hemos destacado, donde se incide de forma decidida en resaltar los elementos sustentantes de los sustentados mediante la bicromía negro/rojo ${ }^{15}$, nos interesa señalar la bipartición que de la estancia se hace a través de una pilastra en estuco que compartimenta el espacio decorativo dividiéndolo en $1 / 3 \cdot 2 / 3$. De esta forma, aunque su excavador no indica si la decoración experimentó algún cambio, tanto en las paredes como en el pavimento, queda perfectamente definida la función de la habitación como cubiculum en el que se reserva el tercio inferior para la alcoba, donde estaría ubicado el lecho, y el resto cumple la función de antecámara, cuya irregularidad en planta debió permitir colocar algún armario.

Por tanto, la concepción general de la estancia tanto en el plano arquitectónico como en el decorativo, junto con la división zonal en dos partes claramente separadas por una pilastra en estuco, nos están indicando no sólo la funcionalidad de la misma como dormitorio, sino toda una compleja gama de influencias que aglutina la casa itálica y cuyo influjo se deja sentir claramente en Contrebia Belaisca, siendo este ejemplo uno de los más antiguos conocidos hasta el momento en España.

\subsubsection{Caminreal (Teruel)}

El yacimiento de "La Caridad" se encuentra ubicado en el término municipal de Caminreal (Teruel). Las excavaciones practicadas hasta el momento han permitido individualizar dos insulae, cuyo período de vida oscila, según sus excavadores, entre la segunda mitad del siglo $\|$ y el primer tercio del siglo । a.C. ${ }^{16}$. No obstante, en algunas zonas del yacimiento se han hallado restos muebles que permiten alargar el hábitat hasta época altoimperial ${ }^{17}$.

En este trabajo nos interesa la Casa 1.1 de la Insula I, también denominada "Casa de Likine" por el rótulo que muestra en íbero uno de sus pavimentos y que le confiere esa denominación ${ }^{18}$. Sin duda, las es-

fig. 29 ss. Martin, R., Manuel d'Architecture Grecque. Paris 1965, fig. 190. Bezerra de Meneses, V.T., "La peinture" en Ph. Bruneau y Ducat, J. Guide de Délos. Paris 1983, págs. 81 ss.

14 Beltrán, M. "Secaisa, Segeda, Poyo de Mara y Durón de Belmonte (Calatayud)", Arqueologia 92. Zaragoza 1992, fig. 234.

15 Beltran, A., op. cit. (1991), pág. 186.

16 Vicente Redon, J.D. et alii, "La Caridad (Caminreal, Teruel)", La casa urbana hispanorromana. Zaragoza 1991, pág. 82

17 Ibidem.

18 VICENTE REDON, J.D. et alii, "Un pavimento de opus signinum con epígrafe ibérico", Actas de la 1:a Mesa redonda Hispano-Francesa sobre mosaicos romanos. Madrid 1989, págs. 11 ss. 
tancias que menos dificultad entrañan en su identificación funcional son la (4) y (13), definidas como cubicula, y que vamos a comentar sucintamente (fig. 2.2.).

Ambas tienen su acceso por un amplio patio ${ }^{19}$. La (4) de $3,24 \times 2,40 \mathrm{~m}$, estuvo pavimentada con un opus signinum en el que claramente se deslinda la zona dedicada al lecho, decorada con retícula de rombos, y la zona de tránsito con meandros de esvásticas alternando con cuadrifolios. La decoración parietal conservada corresponde únicamente al zócalo. Éste, pintado de negro, presentaba medias columnas de estuco de 17,5 $\mathrm{cm}$ de diámetro de color rojo, hecho que ya habiamos visto en un $\mathrm{cu}$ biculum de la denominada Casa Agrícola de Contrebia Belaisca.

La estancia (13), de dimensiones similares a la (4), tiene pavimento de mortero sin ninguna decoración. Aunque no se conservan las pinturas del zócalo, han quedado marcadas en el pavimento las improntas de las semicolumnas, de $0,29 \mathrm{~m}$ de diámetro, que tuvo adosadas a las paredes ${ }^{20}$.

Los rasgos de los dos cubicula comentados permiten formular una serie de consideraciones de gran interés. En primer lugar, la paleta de colores utilizada en el cubículo (4) de la Casa de Likine, es idéntica a la del cubículo (4) de la Casa Agrícola de Contrebia Belaisca, cuyo programa decorativo encaja dentro de los cánones del I estilo. En segundo lugar, la funcionalidad de las habitaciones (4) y (13) de la Casa de Likine viene definida no solamente por la posición que ocupan dentro de la planta general de la domus, sino también por los programas ornamentales y la inclusión de ciertos elementos arquitectónico-decorativos como son las semicolumnas de estuco. Todo este cúmulo de elementos sirve para definir estas dos pequeñas habitaciones como dormitorios donde la alcoba y la antecámara, o lo que es lo mismo el coeton y procoeton, están claramente diferenciadas.

Sin embargo, al contemplar globalmente dichas estancias hay una serie de aspectos que nos producen cierta extrañeza. En primer lugar, no existe un programa unitario a la hora de ejecutar pavimentos y pinturas. Si observamos detenidamente la compartimentación espacial de la estancia (4) a través de la decoración del pavimento, la relación entre alcoba y antecámara obedece al canon 1/3-2/3, mientras que las semicolumnas de estuco adosadas a las paredes se disponen casi a 1/2-1/2. Este hecho indica que el pavimento fue ejecutado según un cartón «standar", con

19 VICENTE RedON, J.D., et alii, op. cit. (1991), fig. 7.
20 


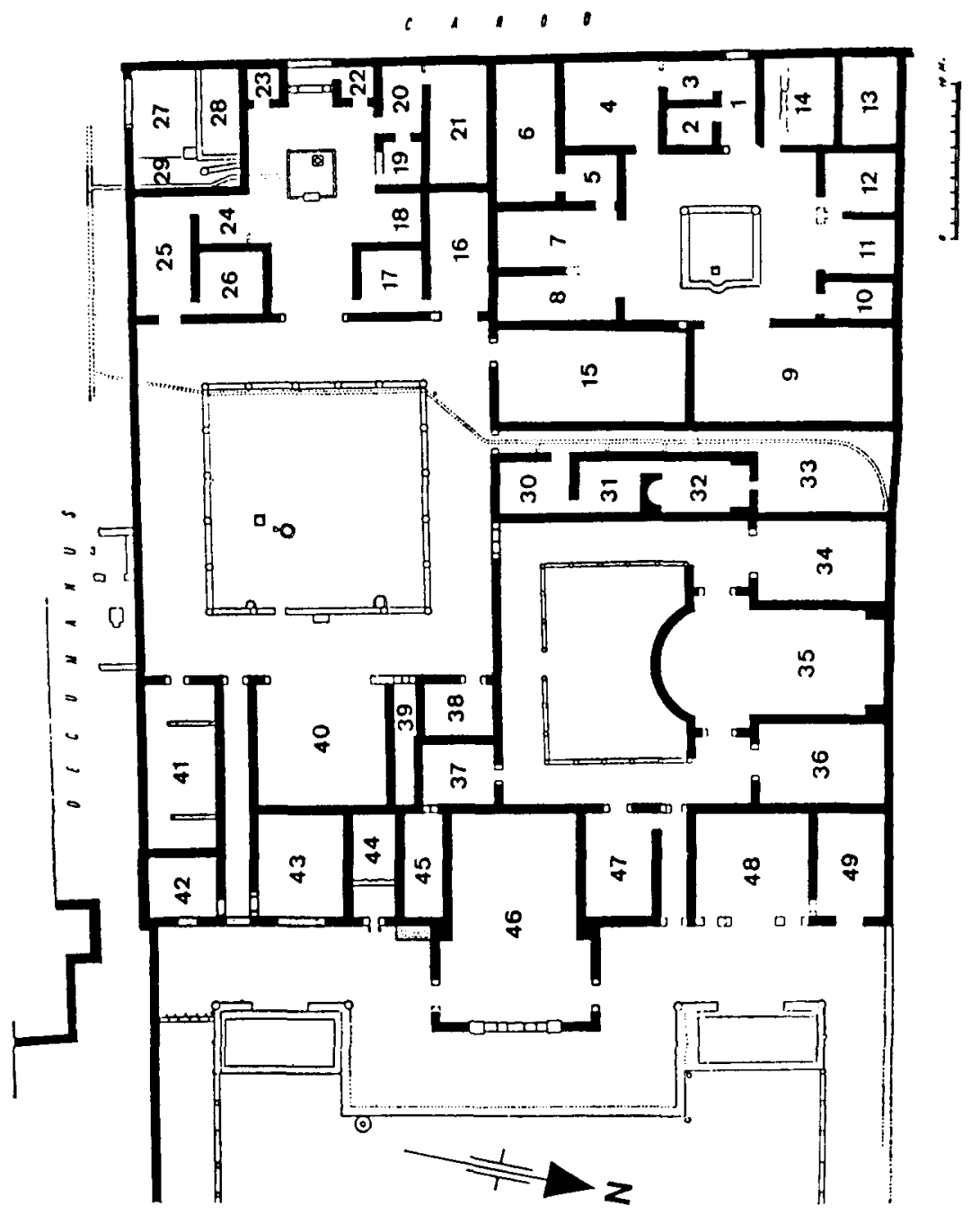

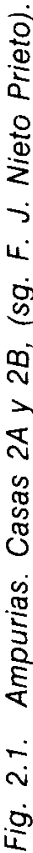




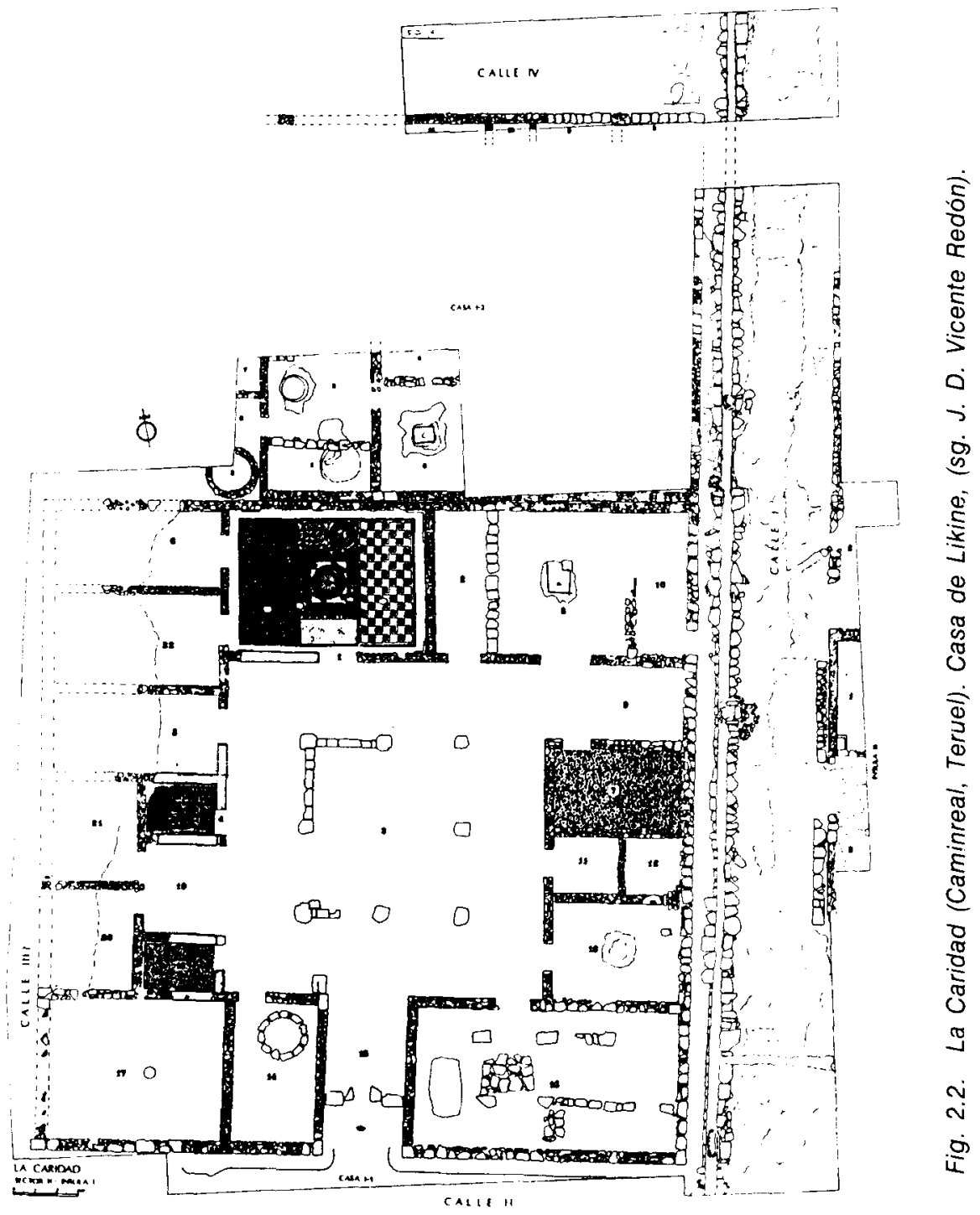


unas medidas no acordes con la realidad y sin tener en cuenta las medidas reales del lecho que iba a colocarse en esta habitación, circunstancia que obligó con posterioridad a los tectores a retroceder la ubicación de las semicolumnas creando de esta forma una cierta anarquía compositiva en el esquema general de la habitación. Por lo tanto musivarios y pintores trabajaron separadamente.

El segundo aspecto, ciertamente peculiar, se refiere a la pavimentación de ambos cubicula. Si realmente se diseñan dos dormitorios gemelos y la funcionalidad de los mismos, está atestiguada por su disposición dentro del esquema arquitectónico y en la habitación (4) se recalca por las pinturas y pavimento, ipor qué la (13) se pavimenta con mortero blanco sin señalar la distinción entre antecámara y alcoba que únicamente viene sugerida por las semicolumnas adosadas a las paredes? ison realmente coetáneos los pavimentos de opus signinum, los de mortero blanco, las pinturas y las semicolumnas adosadas? Para responder estas preguntas deberíamos comprobar si existen realmente en la casa una serie de actuaciones, quizá poco distantes en el tiempo, que motiven los fenómenos indicados.

Sin embargo, estas cuestiones no empañan en la Casa de Likine una realidad patente, como ya habíamos visto en Contrebia Belaisca: la antigüedad de su planta, en la que todavía no está completamente definida la función triclinar, y ciertos influjos del mundo helenístico que aglutina la casa itálica y que, a través de ella, se dejan sentir de forma patente en los dos cubicula tratados según los programas arquitectónico-decorativos puestos en práctica.

\subsection{II estilo. (Características generales)}

Los cubicula relacionados con pinturas y pavimentos del II estilo, o construidos en el período de tiempo en que se desarrolla éste, presentan unas características propias y bien definidas. En ellos la decoración pictórica y musiva marcan las líneas fundamentales que los caracterizan ${ }^{21}$.

Estructuralmente difieren de los relacionados con el I estilo aunque tengan cubierta mixta (plana/abovedada). La distinción entre alcoba y antecámara se realiza mediante el programa decorativo, es decir la alcoba no está realzada en la estructura arquitectónica como habíamos visto precedentemente, sino que forma una unidad y es la decoración conjunta de

21 EliA, O., op. cit. (1932), págs. 409 ss. BARBET, A., op. cit. (1985), págs. 58 ss. 


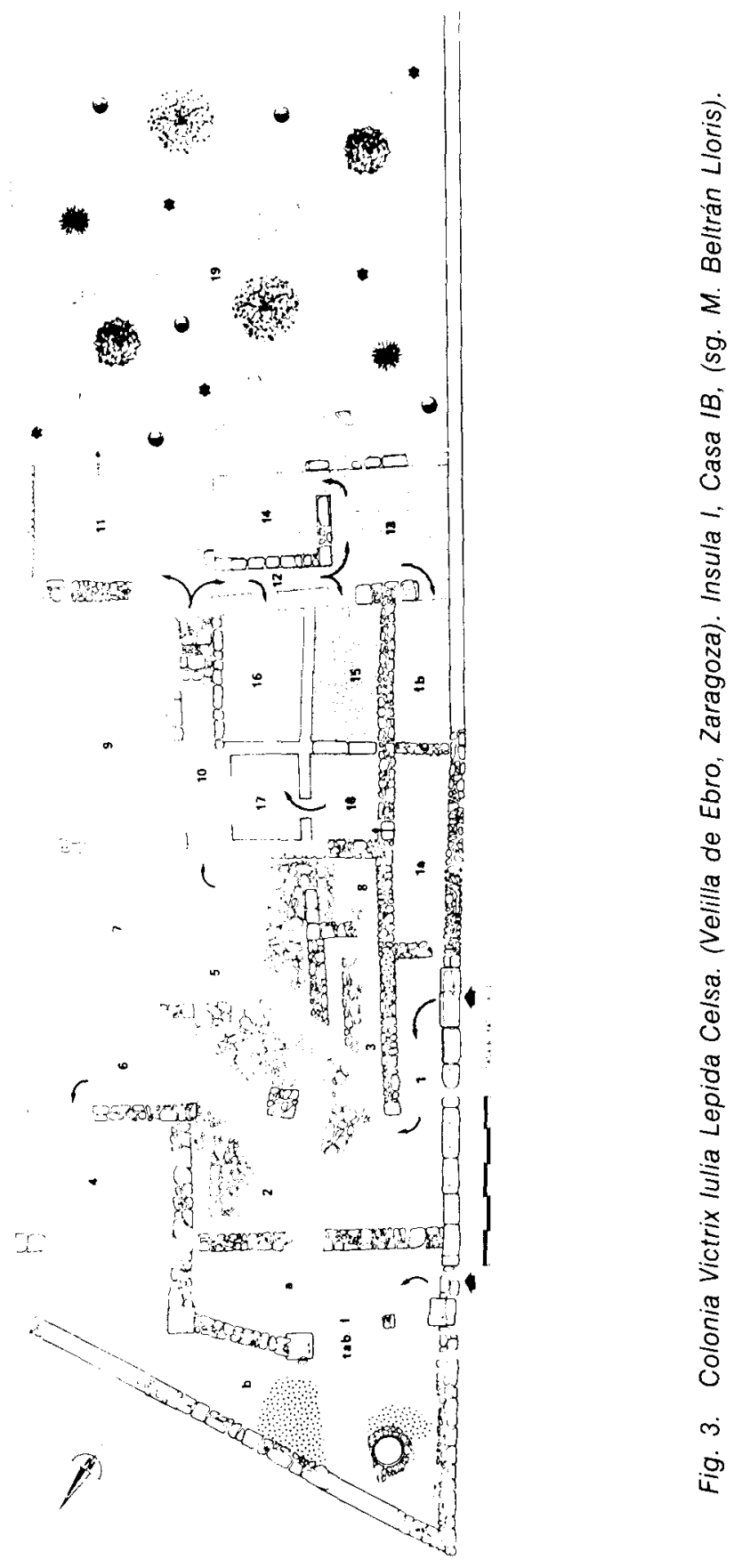


techo, paredes y pavimento la que marca la compartimentación. De ahí que la línea de división ideal entre alcoba y antecámara venga sugerida por pilastras o columnas pintadas.

Ahora encontraremos cubicula dobles, diurnos, nocturnos, etc., dependiendo de la orientación y lugar en que estén dispuestos en la planta arquitectónica. El muro de la antecámara se rasga parcialmente mediante la inclusión de vanos y a la alcoba se la dota de luneto. La decoración pictórica, mediante arquitecturas ficticias ayuda a crear diferentes planos ópticos dando sensación de profundidad y amplitud a las estancias. En este sentido hay que indicar que los programas decorativos parietales en la alcoba presentarán una escala menor que los desarrollados en la antecámara. Sin embargo, no debemos olvidar que éstos son rasgos generales y que, en ciertos casos perduran algunas de las características ya comentadas al hablar de los cubicula del l estilo, y así no es extraño que se sigan utilizando pilastras de estuco. En muchas ocasiones, del poder adquisitivo del cliente junto al lugar de origen de los artesanos serán los rasgos definitorios para poder explicar las peculiaridaes que presentan algunos cubicula.

\subsubsection{Colonia Victrix Iulia Lepida-Celsa}

La Colonia Victrix lulia Lepida se encuentra ubicada en las proximidades de Velilla de Ebro (Zaragoza). Fue fundada en el año 44 a.C. por $M$. Aemilio Lepido y con Augusto cambia de nombre denominándose entonces Colonia Victrix lulia Lepida Celsa. Las estratigrafías obtenidas, así como la cultura material mueble e inmueble indican que Celsa se abandona con Nerón ${ }^{22}$, heredando su protagonismo a partir de ese momento la vecina Caesaraugusta (Zaragoza) ${ }^{23}$.

De la insulae excavadas hasta el momento hemos seleccionado para este trabajo los cubicula de la Casa B de la Insula I, que son fiel reflejo de los expuesto hasta el momento, y que manifiestan per se las diferentes

22 Beltán, lloris, M.; Mostalac Carrillo, A.; lasheras Corruchaga, J.A., Colonia Victrix Iulia Lepida-Celsa (Velilla de Ebro, Zaragoza). I. La arquitectura de la "Casa de los Delfines". Zaragoza 1984, pág. 63. Beltran Llonis, M., Celsa. Zaragoza 1991, págs. 25-27.

${ }_{23}$ Cesaraugusta comienza a manifestar su esplendor a partir del reinado de Tiberio. EI proyecto de remodelación urbana practicado en el interior de su recinto amurallado conlleva, no sólo el replanteamiento de la red de cloacas, sino también la construcción de un nuevo recinto forense, de un templo hexástilo y del teatro, Cf. MOSTALAC, A., "LOS edificios romanos de carácter público de la plaza de La Seo", en Huellas del pasado. Zaragoza 1993, págs. 14-21. 


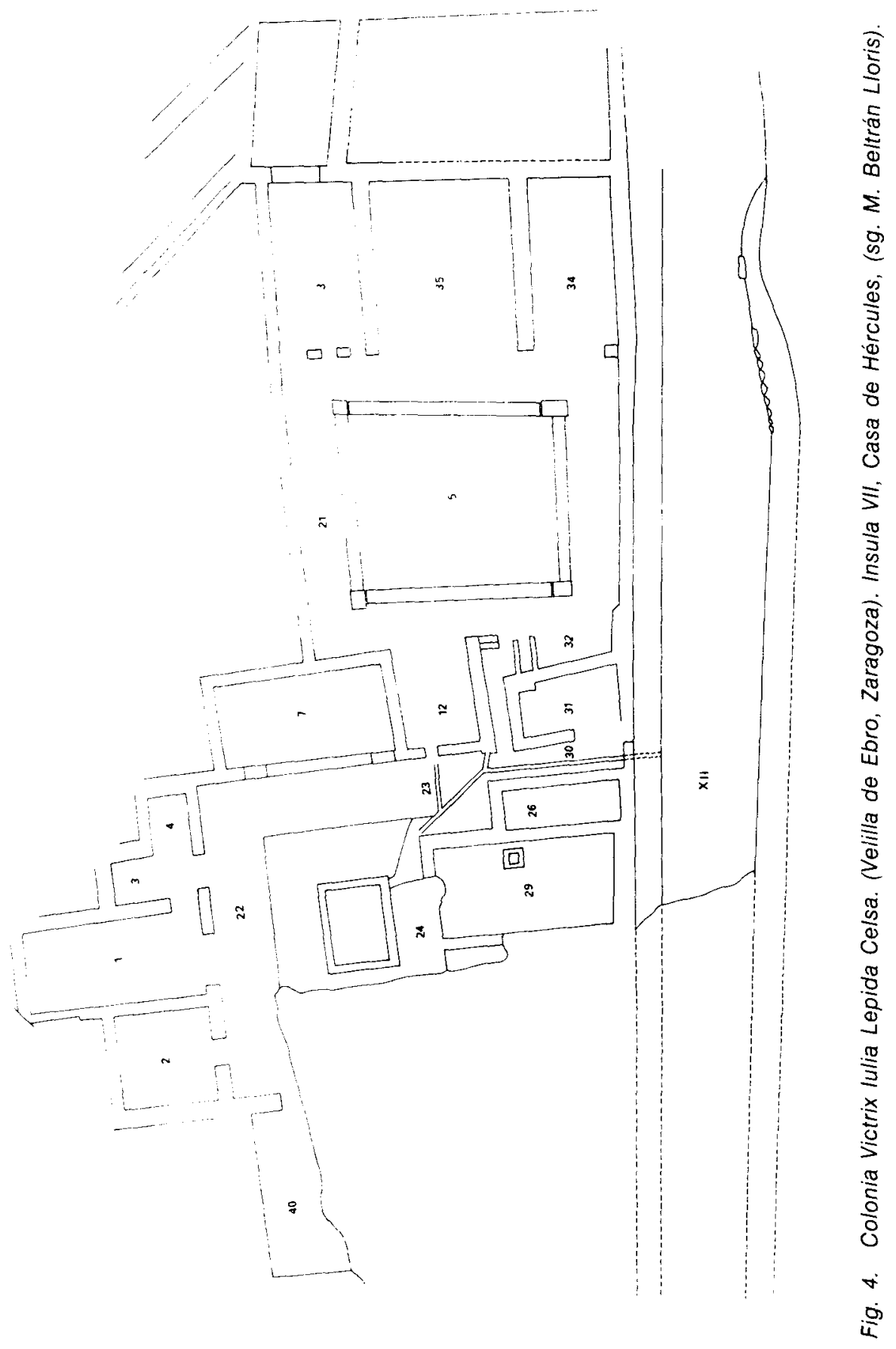




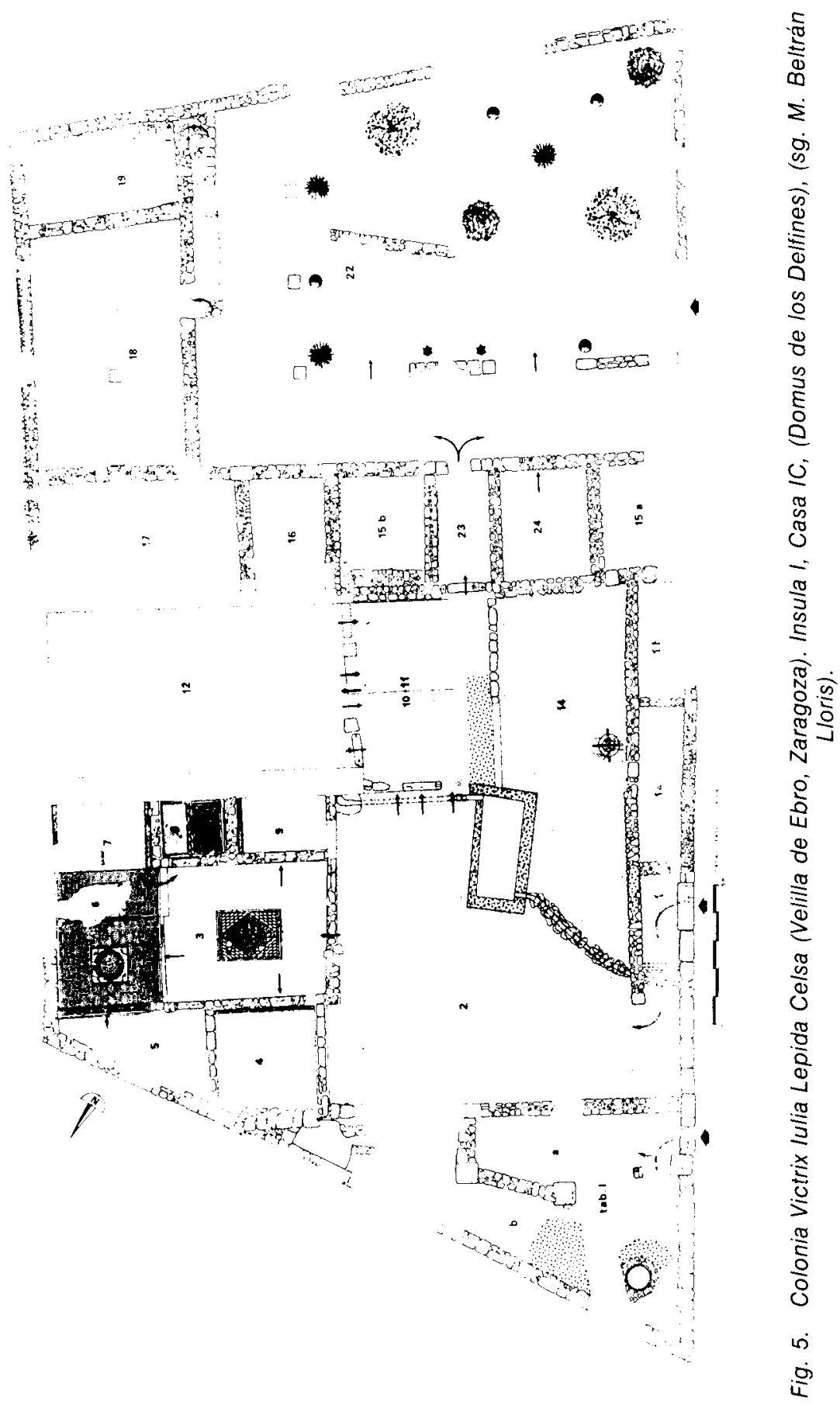




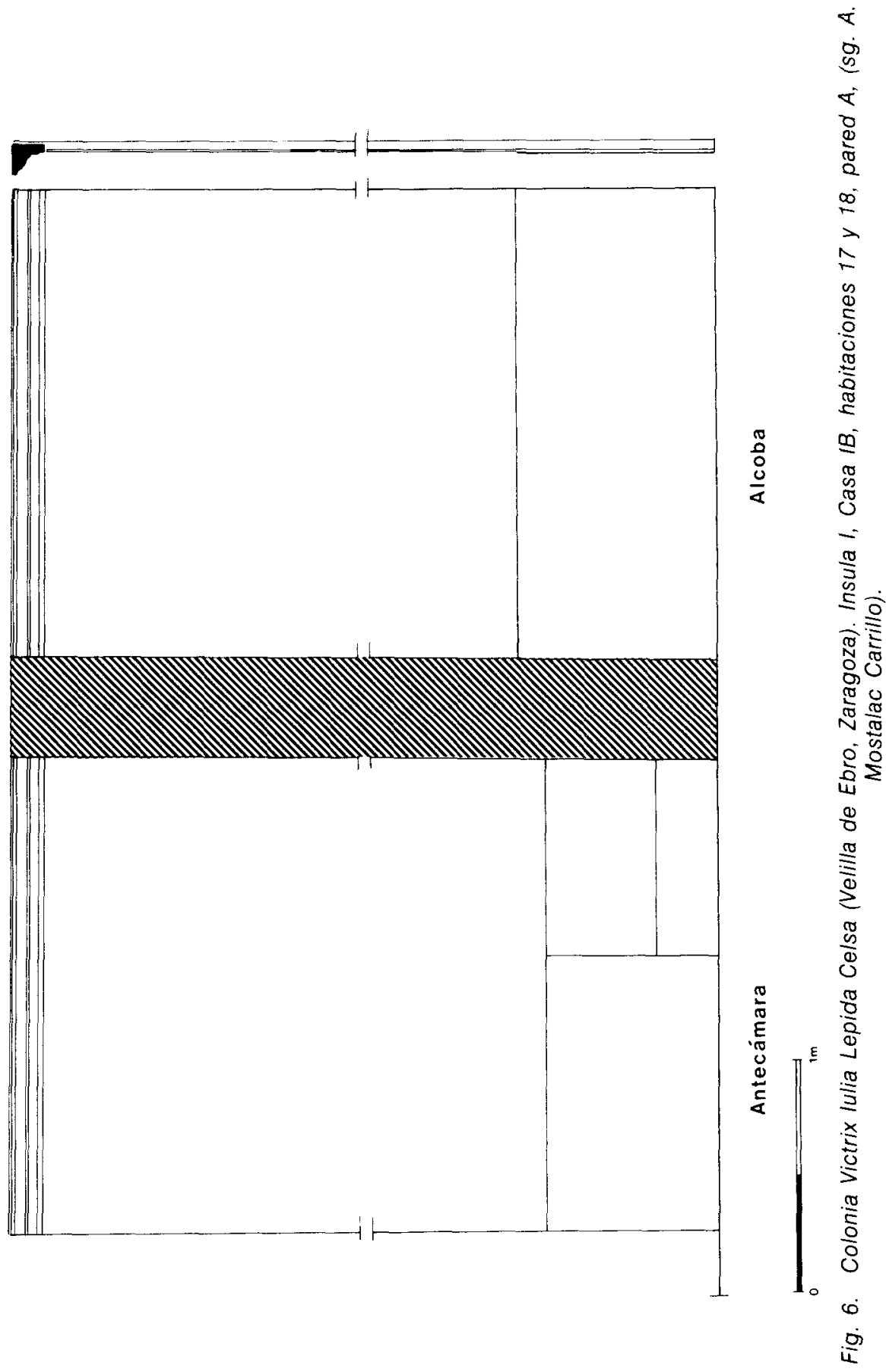




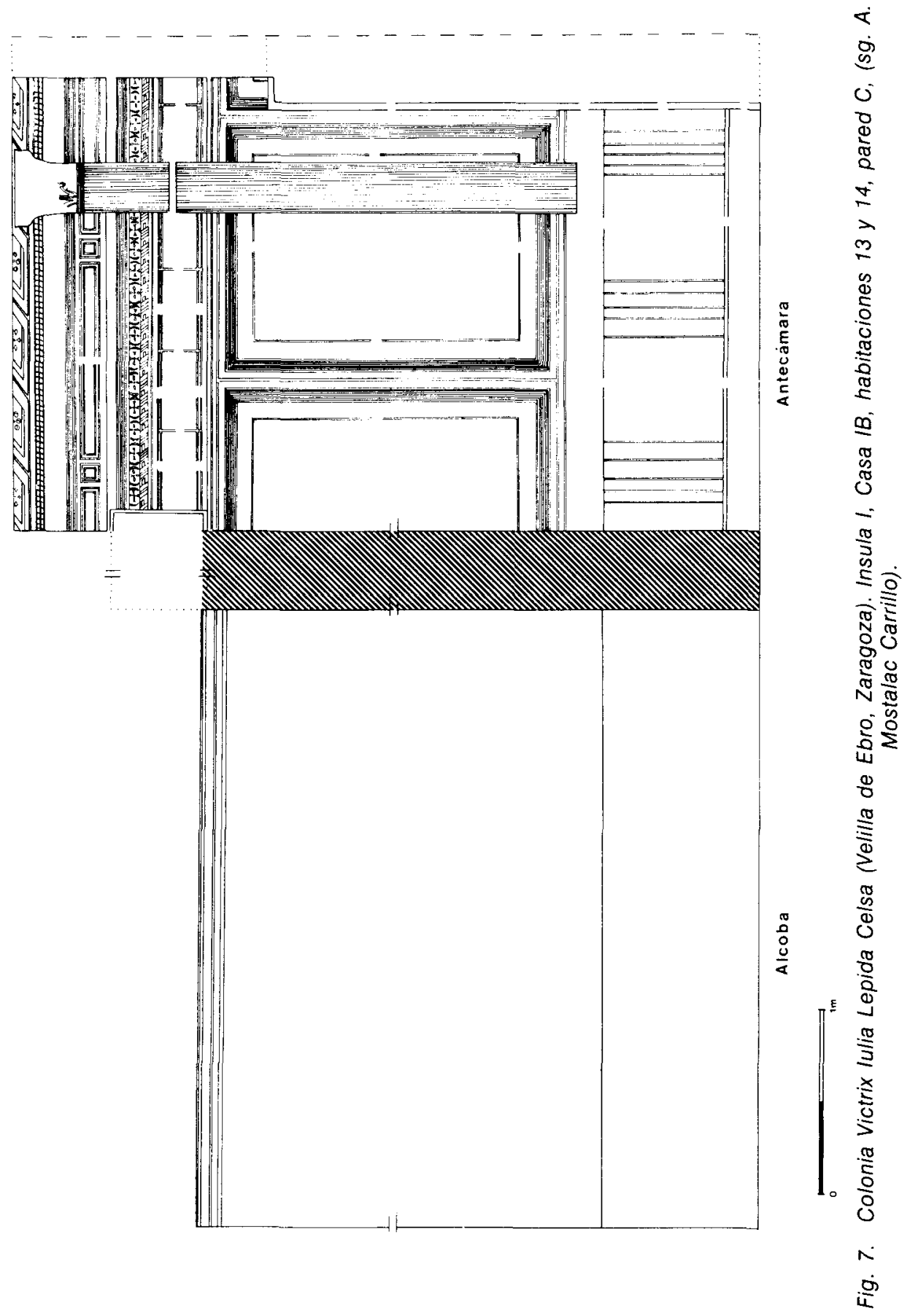




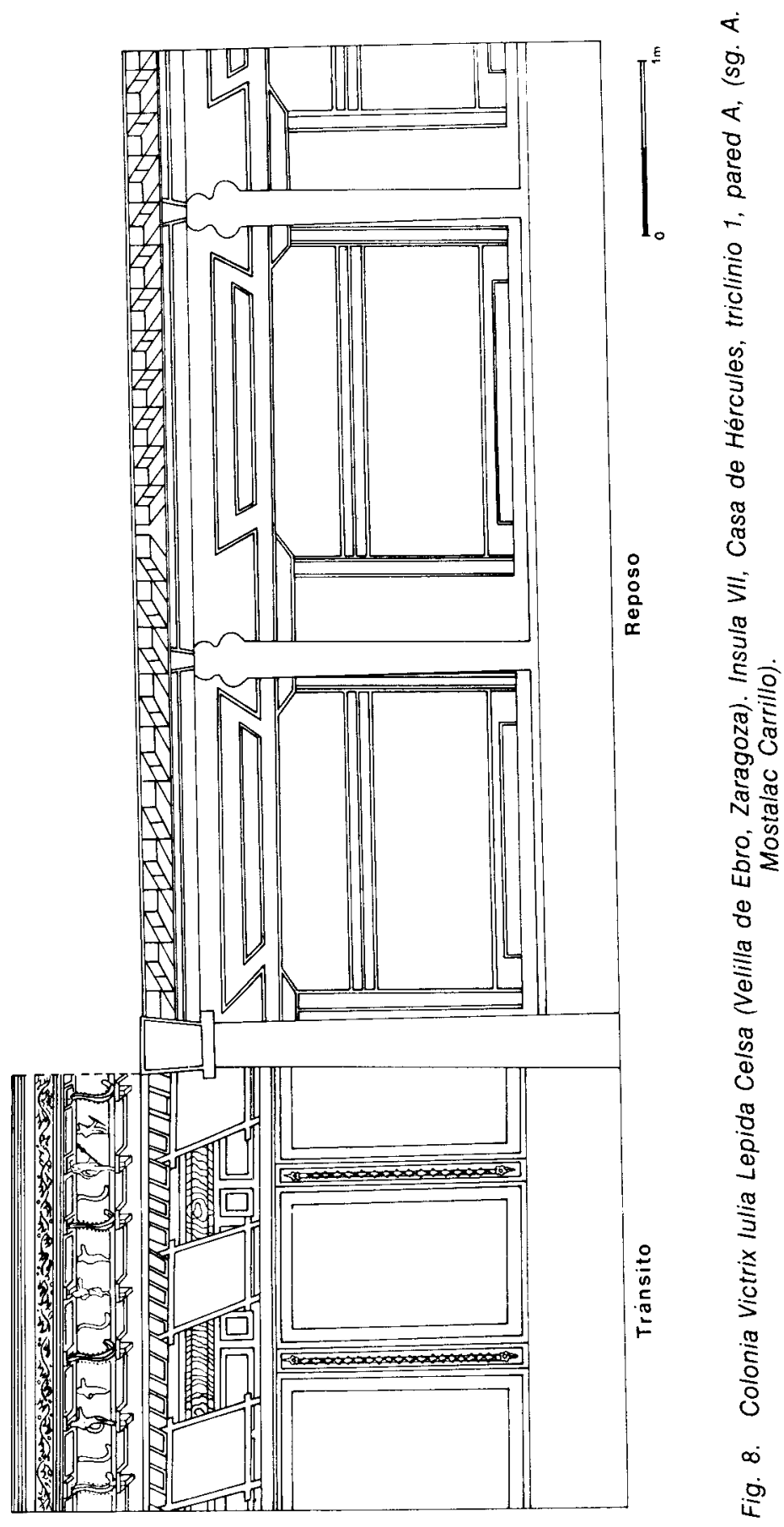



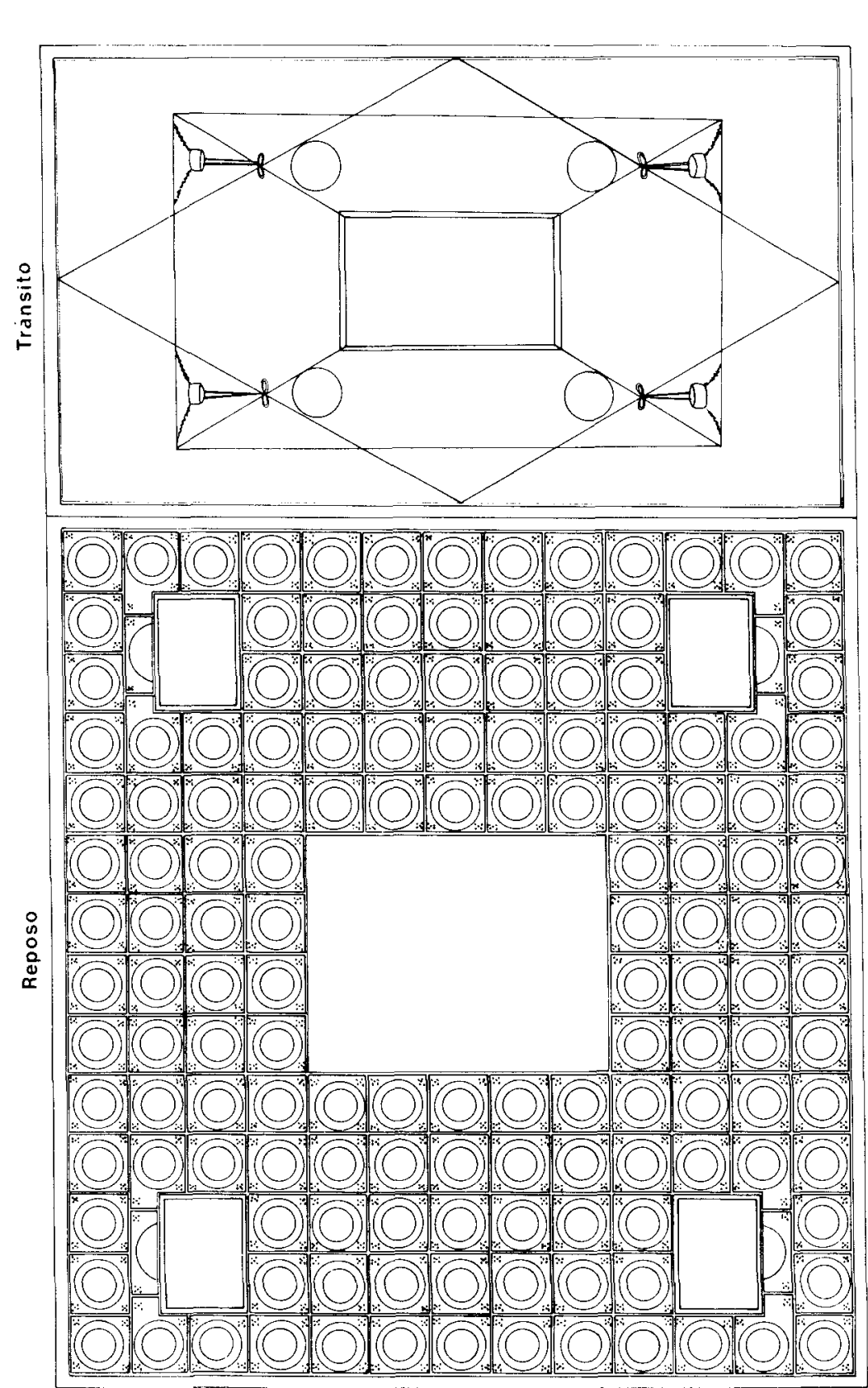

$\frac{8}{0}$

O

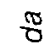

$\frac{1}{8}$

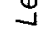

$\stackrel{9}{3}$

$\frac{x}{5}$
$\frac{x}{5}$
$\frac{\pi}{5}$
$\frac{0}{0}$

क

i 
influencias que experimentaron este tipo de estancias en época tardorrepublicana.

De los diecinueve espacios que conforman la planta de la casa B (fig. $3)$, nos interesa resaltar las habitaciones (17) y (18) que responden a un claro cubículo nocturno y la (13) y (14) que hemos interpretado como cubículo/diurno/nocturno. El primero recibió iluminación interior desde el atrio y el segundo desde el jardín ${ }^{24}$.

Las estancias (17) y (18) forman parte de una misma unidad aunque sus funciones sean diferentes. Asi la (17) es la alcoba con pavimento blanco sin decoración. Las cuatro paredes presentan "zocollo sporgente" típicamente campano con zócalo rojo y parte media blanca. El remate de la pared se efectúa con cornisas estucadas de cima recta, que dan paso al techo abovedado, también pintado de blanco. La estancia 18 cumple las funciones de antecámara. En ella hay un banco de obra para sentarse y una plataforma también de obra para colocar un armario o mueble similar. La decoración musiva y parietal es la misma que la de la alcoba. Aunque no existen pilastras de estuco que, en este caso, se han suplido por un murete medianil, la importancia de la decoración parietal radica en su origen típicamente itálico y para ser más precisos campano ${ }^{25}$ (fig. 6). El “zocollo sporgente» o zócalo saliente es un tipo de revestimiento atestiguado ya desde época helenística y que se halla difundido además

24 Mostalac, A., op. cit. (1990).

25 Mostalac, A. y Pérez, J.A. “La excavación del Foro de Cesaraugusta”, en La plaza de La Seo. Zaragoza. Investigaciones Histórico-Arqueológicas. Zaragoza 1989, págs. 134-135. Mos. tAlaC, A., op. cit. (1990). Mostalac, A. y Beltrán, M. Colonia Victrix lulia Lepida-Celsa (Velilla de Ebro, Zaragoza). II Estratigrafía, pinturas y cornisas de la "Casa de los Delfines", (en prensa).

26 FillPPo BONDI, S., "El urbanismo y la arquitectura”, en Los Fenicios. Milán 1988, pág. 260.

27 Bulletin de Correspondance Hellénique XIX (1985), pág. 492, lám. V Id. VIII (1984), lám. XXI; ldem, XIX (1985), pág. 488, lám. 3. Bularo, M., op. cit. (1908), pág. 99 nota 1 y 2.

${ }_{28} \mathrm{MAU}, \mathrm{A}$., Geschichte der dekorativen Wandmaleri in Pompeji. Berlin 1882, pág. 33. BRAGANIINI, 1.; VOS, M. de y PARISE, F., Pitture e pavimenti di Pompei. Regioni. I, II, III. Roma 1981. Bragantini, I; Vos, M. de Parise, F. y Sampaolo, V., Pitture e pavimenti di Pompei. Regioni $V y$ VI. Roma 1983. Id., Regioni VII, VIII y IX, Roma 1986. Parte de los ejemplos reseñados en las obras citadas en esta nota, pueden cotejarse en las ilustraciones de los tres volúmenes aparecidos hasta el momento de la obra: Pompei. Pitture e mosaici. Roma, Istituto della Enciclopedia Italiana (1990) I-II-lll y V.V.A. A., La peinture de Pompéi. Paris, 1993.

29 Mostalac, A., op. cit. (1990).

30 Ibidem.

31 Ibidem.

32 RUYt, C. de Macellum. Marché alimentaire des romains. Louvain-La Neuve 1983, págs. 86 ss.

33 Carandini, A., (a cura di), Settefinestre. Una villa schiavistica nell'Etruria romana. Modena 1985 , t. II, págs. 60 ss., lám 5. 
de Cartago ${ }^{26}$, Delos ${ }^{27}$, Pompeya ${ }^{28}$, Herculano ${ }^{29}$, Roma ${ }^{30}$, Ostia ${ }^{31}$, Ordona ${ }^{32}$ y Settefinestre ${ }^{33}$, por una gran parte de la Campania, siendo Pompeya la ciudad donde está atestiguado con mayor amplitud.

Las estancias (13) y (14) responden a un planteamiento arquitectónico similar al del cubículo comentado precedentemente (fig. 7). Sin embargo en este caso, aunque la alcoba etá plenamente individualizada - con un hueco en uno de sus muros, a modo de testero, donde iría el lecho, decoración parietal con "zocollo sporgente" y pavimento de terrazo blanco-, a la antecámara se le ha dotado de una función doble, por una parte, la propia; y por otra, como zona de tránsito.

La antecámara presenta un sistema compositivo basado en un esquema arquitectónico sobrio, donde el repertorio ornamental y ciertos aspectos compositivos llevan a fechar tales pinturas entre los años 40-30 a.C. ${ }^{34}$.

\section{TRICLINIA}

\subsection{Estilo. (Características generales)}

Comparando los esquemas de cubicula y triclinia vemos que el principio que los ha inspirado sigue las mismas normas decorativas. Es decir, encontramos una división en dos zonas que, en ocasiones, aparece marcada indistintamente en suelos, pavimentos y paredes. De acuerdo a los restos conservados fundamentalmente en Pompeya, hay una regla que los rige: la zona de ingreso representa $1 / 3$ de la longitud, mientras que la zona de recepción ocupa los 2/3 restantes, salvo en aquellos casos donde las habitaciones son muy pequeñas, utilizando en este caso la relación 1/1. Esta relación entre las proporciones citadas incide de forma directa en los esquemas compositivos elegidos, ya que la escala de los elementos pintados será mayor en la zona de recepción que en la de tránsito. Por tanto, el fenóneno que se produce en los triclina es el inverso al detectado en los cubicula.

Al observar los programas ornamentales resalta otro hecho: la tendencia a centralizar elementos decorativos con el fin de fijar desde la entrada la atención del espectador. Por ello se eligerı esquemas grandiosos donde imperan temas arquitectónicos con el consiguiente interés en ampliar el espacio, dar sensación de profundidad y crear, en definitiva,

34 Mostalac, A. y Beltrán, M., op. cit. (en prensa). 
una atmósfera típica. Pavimentos y cubiertas refuerzan esta sensación incorporando, en ocasiones elementos curvos y planos separados por pilastras pintadas o estucadas ${ }^{35}$.

En España hay dos yacimientos fundamentales para entender este proceso: Ampurias y la Colonia Lepida.

\subsubsection{Emporiae (Ampurias). Insula II, Casa 2B}

La presencia romana en Ampurias se inicia con el desembarco de un cuerpo expedicionario al mando de Cneo Escipión y se materializa entre los años 195-175 con la creación de un campamento estable del ejército donde hoy se halla la ciudad romana. Hacia el año 100 esta presencia cristaliza en una ciudad de nueva planta en la que se insertan un serie de ínsulas de enorme interés ${ }^{36}$.

Se debe a F. J. Nieto el haber descubierto que la Casa 2 (fig. 2.1.) estaba integrada por dos unidades, que denomina $2 \mathrm{~A}$ y $2 \mathrm{~B}^{37}$. A partir de ese momento diferentes autores han ido deslindando las diversas fases arquitectónicas que conformaron la estructura arquitectónica que hoy podemos contemplar ${ }^{38}$. De ese conjunto vamos a tratar la unidad denominada $2 B$ que, en su fase inicial, debió estar formada por unos quince espacios. De ellos analizaremos el (16), sin identificar funcionalmente hasta el momento, y que creemos que corresponde a un triclinium como seguidamente podremos comprobar. Nos interesa ahora reparar en la descripción que de esta estancia se hace en los diarios de excavación: “(...) Debió poseer una interesante decoración pictórica, teniendo en cuenta los restos que aún permanecen. Mide la habitación 3,80 por 7,93. Hacia la mitad se ven dos resaltes verticales en el muro, a uno y otro lado, que se corresponden de frente, como si se hubiese querido hacer una división en la alcoba. Desde la entrada a estos resaltes la decoración pictórica es

35. A los trabajos citados en la nota 6 habría que añadir el de BARBET, A., "Quelques raports entre mosaïques et peintures murales a l'epoque romaine" en Recueil d'Hommages a Henri Stern. Paris 1983, págs. 43-53. Richardson, Jr. L., "A contribution to the study of Pompeian dining-rooms", Bolletino dell'Associazione Internazionales Amici di Pomepi / (1983), págs. 6171.

36 Sanmarti, E. y Nolla, M. ${ }^{3}$, Ampurias. Guia Itineraria. Barcelona 1988.

37 Nieto Prieto, J.F., "Repertorio de la pintura mural romana de Ampurias", Ampurias 41 42 (1979-1980), págs. $279-342$.

38 Sobre un estado de la cuestión cf. SANTOS Retolaza, M., "Distribución y evolución de la vivienda urbana tardorrepublicana y altoimperial en Ampurias", La Casa Urbana Hispanorromana. Zaragoza 1991, págs. $19-34$ y especialmente, págs. 31 ss. 
de guirnaldas vinosas. La otra parte de la habitación se decora con motivos geométricos en forma de basamentos sobre paneles de color rojo purpúreo $(\ldots){ }^{39}$.

En el texto que acabamos de reproducir hay tres detalles que queremos resaltar. El primero, las dimensiones de la sala; el segundo, las pilastras adosadas a la pared compartimentando el espacio y, el tercero, la diferenciación de la zona de tránsito de la de reposo mediante una decoración de guirnaldas suspendidas y sistema arquitectónico.

Lamentablemente los restos pictóricos conservados en la actualidad son muy escasos para inferir de ellos una cronología aquilatada, hecho que se deriva de las pinturas de otras estancias de la casa y que se pueden situar entre las fases II a y II b del II estilo, cronología seguramente válida también para el pavimento de esa habitación ${ }^{40}$.

Pero volvamos al programa pictórico. La estancia (16) tuvo en su inicio una serie de guirnaldas vinosas. Esta decoración, ubicada en el ingreso de la habitación, suele ser típica de los programas decorativos desarrollados en la zona de recepción o de tránsito de los triclinia y ha servido, en ocasiones, para matizar la funcionalidad de las mismas, criterio que aplicamos a la habitación que analizamos ${ }^{41}$. Tras la decoración de las guirnaldas, sendas pilastras de estuco, que separan y compartimentan físicamente no sólo la decoración sino el espacio, creando de esta forma dos zonas: una de tránsito y otra de reposo. Si en la primera parte de la habitación hubo sucesión de guirnaldas, en la segunda se utiliza un esquema arquitectónico ${ }^{42}$. En él se desarrollan pedestales alternando con compartimentos, todo ello con una incipiente perspectiva y diferentes puntos focales, que ayudan a crear una atmósfera ficticia. Indudablemente en la zona media existieron columnas, ortostatos e interpaneles, a tenor de los esquemas conservados en otras habitaciones de la misma casa. En el sistema compositivo del área de reposo, desde luego, reina una clara planitud fruto de la simplificación del esquema arquitectónico representado, que matiza claramente su cronología. Sin embargo, no es sólo la

as Nieto Prieto, F.J., op. cit. (1979-1980), pág. 324

40 En otra ocasión ya hemos indicado que la cronología dada a algunas pinturas de esta misma casa es ciertamente desmesurada, cf. Mostalac, A., op. cit. (1992), págs. 9-22. Por otra parte, los pavimentos de opera signina de la casa pueden datarse en la primera mitad del siglo i a.C., cf. Ramallo Asensio, S., "Talleres y escuelas musivas en la Península Ibérica", Mosaicos romanos. Estudios sobre iconografia. Actas del Homenaje in Memoriam de Alberto Balil Illana. Guadalajara 1990, págs. 140-141, lo cual no está en desacuerdo con la cronología que proponemos en torno a los años 40 a.C. o incluso un poco más tarde.

41 Barbet, A., op. cit. (1985), pág. 68.

42 Nieto Prieto, F.J., op. cit. (1979-1980), pág. 326, fig. 62. 
decoración la que está indicando el uso de la habitación, sino también la posición que ocupa este espacio en la planta general de la casa. Por tanto, en la estancia (16) de la Casa 2B observamos una clara simbiosis entre arquitectura y pintura con un fin muy claro: la definición funcional de la misma.

\subsubsection{Colonia Lepida}

De la Colonia Lepida hemos elegido la Insula VII y, de ella, la denominada Casa de Hércules (fig. 4). Esta vivienda destaca por presentar un atrio toscano al cual se abre el triclinium que nos interesa, y un patio porticado que centralizaba el circuito de acceso a diversas estancias de reposo. La Casa de Hércules sufre importantes remodelaciones desde época de Augusto hasta su abandono en el reinado de Nerón ${ }^{43}$.

El triclinium (1), situado axialmente en la planta de la casa, presenta pavimento de opus signinum dividido en dos zonas iguales. Las paredes estuvieron decoradas con pinturas del II estilo con unos programas ciertamente progresistas si los cotejamos con el cartón utilizado para el pavimento. El techo, a su vez, era plano en el inicio para pasar a abovedado en el fondo de la habitación. Por lo tanto vemos un decidido interés en el programa arquitectónico-decorativo utilizado en esta habitación, por marcar y compartimentar el espacio físico. Sin embargo, se producen una serie de contradicciones en el programa de esta estancia que quisiéramos comentar. El pavimento marca claramente la modulación de $1 / 1$ en la división decorativa, separando netamente la zona de tránsito de la de reposo. Sin embargo, las pinturas de la pared Norte presentan un esquema diferente. La proporción utilizada es $1 / 3-2 / 3$, módulo que coincide con la cubierta, plana en el primer tramo y abovedada en el segundo. El programa pictórico desarrollado, datado en torno al año 40 a.C., es ciertamente interesante. En el primer tercio aparece una secuencia de ortostatos que sustentan cuadros con la representación de los trabajos de Hércules y un entablamento con atlantes, cariátides y friso floral. Esta decoración se separa de la del resto de la pared por una pilastra pintada de blanco que marca intencionadamente tal dicotomía. Una vez pasado el primer tercio de la habitación, entramos en un mundo decorativo diferente; una escenografía teatral, basada posiblemente en la reproducción de un telón móvil de un teatro lígneo, aparece surcada por figuraciones

${ }^{43}$ Beltrán Lloris, M., op. cit. (1991), págs. 25-27 
simplificadas de atlantes, elementos decorativos que definen y matizan la cronología de estas pinturas (fig. 8). El análisis global del programa decorativo de esta habitación indica el interés conjunto de arquitectos, pintores, musivarios y estucadores en definir ornamentalmente la función de la misma. Ahora bien, se observa un hecho ciertamente relevante; el programa pictórico es progresista y está a la moda del momento en que se ejecuta, mientras que el del pavimento es algo retardatario. Si evidentemente tuviéramos que datar cada programa decorativo de forma individual, el pavimento seguramente recibiría una cronología más alta que la que le corresponde al contrastarlo con otros pavimentos en suelo itálico, no así las pinturas o estucos que encajan plenamente con lo que en ese momento se está realizando en otros lugares.

\subsection{III estilo. (Características generales)}

En lo que concierne a las pinturas del III estilo se sigue manteniendo la bipartición y, en ocasiones, se sigue utilizando las pilastras de estuco adosadas a las paredes. Los techos marcan igualmente esta separación y los pavimentos tienden a señalar los puestos de los lechos y mesa, o incluso, a no presentar ninguna decoración. No obstante, al final de la fase IIb del III estilo se observan una serie de elementos que preludian ya un nuevo estilo, aunque los viejos esquemas subsisten ${ }^{44}$.

\subsubsection{Colonia Celsa}

De la Insula I, Casa C, también denominada de los Delfines, se ha conservado todo el programa decorativo de un gran salón triclinar (12) (fig. 5). En él se observa de nuevo la bipartición 1/3-2/3 a través de la estructura de la cubierta. El tercio de entrada es plano y en los dos tercios restantes es abovedado. El programa decorativo es muy simple: el primer tercio presenta figuras geométricas vegetalizadas que enmarcan un emblema con Hércules Bibax y, el resto, simula con pintura un techo casetonado con motivos florales, pequeños cuadritos con Nereidas y un emblema central en el que Venus cabalga sobre dos tritones (Fig 9). Desconocemos la decoración de las paredes, no obstante, el pavimento es de terrazo blanco sin ornamentación que, en este caso, aparece como novedad. Por tanto, la funcionalidad viene indicada por la propia situación

44 Barbet, A., op. cit. (1985), págs. 123-126. 
de la habitación en la casa y por un programa decorativo donde se hace especial hincapié en los emblemas centrales que obligan a dirigir la vista del espectador hacia puntos previamente prefijados.

\section{LA ASOCIACIÓN DE PINTURAS Y PAVIMENTOS DE OPUS SIGNINUM}

Hemos reservado para el final intencionadamente el problema de las influencias itálicas que manifiestan los ejemplos que hemos comentado y su cronología, fundamentalmente la de los pavimentos. Es indudable que las primeras manifestaciones de opera signina asociados a pinturas del I estilo pompeyano no las podemos remontar objetivamente, de acuerdo a los datos que poseemos en la actualidad, más allá de la segunda mitad del siglo II a.C. y con cierta precisión al último cuarto de ese siglo ${ }^{45}$. Las pinturas de Azaila, Contrebia Belaisca o Belmonte de Calatayud parecen marcar por el momento el término post quem, de la introducción de la pintura romana en España asociada a suelos de opus signinum. Sin embargo, es a partir de esa fecha cuando comenzamos a observar la presencia de este tipo de pavimentos no asociados a pinturas y que por relación con otros en suelo itálico se datan en fechas tempranas y se suponen confeccionados por talleres itálicos.

Hay un hecho que no acertamos explicar correctamente. Si en verdad, una de las características de la domus itálica es el gusto por la decoración mural, y el período que tratamos en este trabajo coincide con el nacimiento, pujanza y desarrollo de los cuatro estilos: ¿cómo es posible encontrar tantos pavimentos y tan pocas pinturas? ¿acaso a España sólo llegan talleres de musivarios y no de pintores? idebemos aceptar como verdadero que las paredes se pintaban únicamente de blanco, o sea, económicamente y se invierte más en los pavimentos? ¿quiénes son realmente los clientes?

A esta serie de preguntas podríamos añadir todavia unas cuantas más, pero la nómina sería muy larga y peligroso extrapolar las posibles respuestas de una zona a otra de España. Por ello nos vamos a ceñir al valle medio del Ebro donde este fenómeno parece estar generalizado y algunas de las cuestiones planteadas se pueden, al menos, responder.

Evidentemente los primeros pavimentos de opus signinum llegan al valle medio del Ebro procedentes de Italia, presumiblemente de mano de talleres itálicos ${ }^{46}$. Sin duda, estos talleres vienen a satisfacer los encargos

45 Mostalac, A. y Guiral, C., op. cit. (1992).

46 En esta apreciación estamos de acuerdo la mayoria de los investigadores. Por citar dos 
- la demanda de los inmigrantes itálicos que pretenden rodearse de comodidades, modos de vida y formas propios de las zonas de origen de donde provienen. Junto a los musivarios debieron arribar pictores parietales y estucadores y es justamente en las casas más antiguas donde observamos esta asociación de pinturas, pavimentos y cornisas. Esta llegada parece producirse en torno a la segunda mitad del siglo ॥ a.C. A partir de ese momento los pavimentos de opus signinum siguen realizándose sin solución de continuidad durante todo el siglo I a.C., pero curiosamente es en la primera mitad del siglo । a.C. cuando observamos el fenómeno ya indicado: una completa ausencia de pinturas y un extraordinario apogeo de pavimentos en los cuales se quiere ver un marcado influjo itálico. No hace falta nada más que comparar arquitectura y programas decorativos para comprobar la falta de coordinación entre ellos, en ocasiones, bastante palpable. $Y$ es justamente a partir de mediados del siglo । a.C. hasta bien entrada la época de Tiberio, cuando observamos de nuevo una concordancia entre pinturas, pavimentos y arquitectura y una llegada fluida y contínua de los nuevos gustos y modas coincidentes fundamentalmente con las últimas fases del II, III y IV estilos. ¿Qué podemos deducir de todos estos hechos? Algo que parece cada vez más evidente. En una primera instancia la llegada de talleres itálicos es cierta, estos talleres debieron estar trabajando un tiempo prudencial de acuerdo a los encargos que tuvieran. Acabados éstos regresan y es entonces cuando comienzan a aparecer talleres locales cuyos maestros en algunas ocasiones se permiten firmar su producción como es el caso de Caminreal o Andelos ${ }^{47}$. Estos pavimentos lógicamente presentan repertorios itálicos

artículos relevantes: LASHERAS CORRuChagA, J.A., "Pavimentos de opus signinum en el valle medio del Ebro", Museo de Zaragoza. Boletín 3 (1984), págs. 165-192. Ramallo Asensio, S., op. cit. (1990), pág. 136.

47 En el texto hemos aludido a la similitud que presentaba la paleta de colores de uno de los cubicula (rojo/negro), con el triclinio (4) de la Casa Agrícola de Contrebia Belaisca. Sin embargo, en ninguna estancia de la casa ha aparecido, o al menos no ha sido publicado, ningún fragmento que acredite decoraciones relacionables con el primer estilo como sucedía en Botorrita. Por lo tanto, para Caminreal, únicamente se pueden defender monocromias o bicromías y no decoraciones del l estilo o derivaciones helenísticas. Ello asociado a las peculiaridades de los pavimentos nos lleva a sugerir un término post quem para la construcción de la casa, a comienzos del siglo a. C.

Hemos querido hacer esta apreciación, porque sospechamos que el autor de los pavimentos de opera signina no es de origen itálico y que el rótulo que hace referencia a Likine corresponde al nombre del artífice de los mismos. Un reciente artículo de sus excavadores indica: "Por otra parte, establecido creemos que con suficiente fiabilidad, el carácter ibérico de Likine, su consideración como musivario implicaría la existencia de un artesanado indígena suficientemente especializado, que habria incorporado de forma muy rápida las técnicas constructivas y los repertorios iconográficos vigentes en el Mediterráneo a principios del siglo । a.C.", cf. VICENTE, D. et alii, "Las inscripciones de la Casa de LIKINE (Caminreal, Teruel)", Lengua y Cultura en la Hispania Prerromana. Universidad de Salamanca 1993, pág. 756 
pero en sus composiciones se observan ciertas libertades o reiteraciones que a veces los convierten en unica. Además casi nunca aparecen asociados a pinturas y suelen estar ubicados en ciudades de carácter indígena, cuyo indice romanizador viene marcado, entre otros elementos de la cultura material, por el tipo de pavimentos que tratamos. Este fenómeno curiosamente parece producirse en la primera mitad del siglo I a.C. y coincide con el vacío pictórico de las fases más antiguas del II estilo.

Los ejemplos que hemos expuesto en este trabajo manifiestan claramente la pronta llegada de modelos y talleres centro y suritálicos a nuestro país. Estas influencias, patentes en la arquitectura y programas decorativos, está francamente bien atestiguada en algunos cubicula y triclinia. No obstante, se aprecia un afán premeditado en arquitectos y artesanos por sugerir la funcionalidad, en nuestro caso, de dormitorios y comedores, a través de la decoración de suelos, paredes y techos, sin ahorrar esfuerzos en ampliar ficticiamente el espacio a través de las pinturas, reconducir a través de los circuitos internos de tránsito a las personas, obligar a fijar la atención en determinadas partes de la estancia o valorar la propia arquitectura. Sin embargo, todos estos logros, cuando el trabajo de arquitectos y artesanos no está coordinado, se convierten en anarquía compositiva, surgiendo entonces programas decorativos extraños para los cuales, dadas sus peculiaridades, es difícil establecer relaciones de taller.

Los ejemplos conservados en España, aunque todavía no son numerosos, presentan buena parte de los rasgos enumerados y son fiel reflejo del influjo itálico que experimentó la arquitectura doméstica en época republicana.

Esta hipótesis, que los mencionados autores se plantean, es la misma que parece deducirse de la ausencia de decoraciones pictóricas asociadas a los pavimentos de opera signina en el valle medio del Ebro en la primera mitad del siglo I a.C. El reciente hallazgo de un pavimento de opus signinum con inscripción ibérica en Andelos (Navarra), de la misma fecha que los de Caminreal, donde de nuevo aparece la palabra Likine, parece reafirmar nuestra hipótesis, cf. Mezquiriz, M. ${ }^{a}$ A., "Pavimento de opus signinum con inscripción ibérica en Andelos". Trabajos de Arqueologia Navarra 10 (1991-1992), págs. 365-367 y 439. Sin embargo, para M. ${ }^{a}$ A. Mezquiriz la inscripción que nos interesa podria tratarse de alguna fórmula ritual de acceso a la casa (?.). 